Review article

\title{
Cardiovascular complications during the treatment of castration-resistant prostate cancer with the use of modern antiandrogens: abiraterone acetate and enzalutamide
}

\author{
Radosław Grabysa ${ }^{1,2}$, Agnieszka Chmielewska ${ }^{3}$ \\ 'Department of Internal Medicine, Gastroenterology and Oncological Cardiology, Warmian- \\ -Masurian Cancer Center of the Ministry of the Interior and Administration's Hospital, Olsztyn, Poland \\ ${ }^{2}$ Pulmonology Clinic, Collegium Medicum, Univesity of Warmia and Mazury, Olsztyn, Poland \\ ${ }^{3}$ Oncology and Immunooncology Clinic, Warmian-Masurian Cancer Center of the Ministry of the \\ Interior and Administration's Hospital, Olsztyn, Poland
}

Correspondence: Radosław Grabysa Department of Internal Medicine, Gastroenterology and Oncological Cardiology, Warmian-Masurian Cancer Center of the Ministry of the Interior and Administration's Hospital, Olsztyn, Poland 10-228 Olsztyn, al. Wojska Polskiego 37 e-mail: rgraby@wp.pl

Received: 18.08.2021 Accepted: 10.09.2021

\section{ABSTRACT}

Modern antiandrogens: abiraterone acetate (inhibitor of CYP17 cytochrome) and enzalutamide (irreversible inhibitor of androgen receptor) are the drugs that are increasingly often administered in treatment of castration-resistant prostate cancer. Despite their clinical efficacy, especially in terms of prolonged survival and improved quality of life of patients, they pose of problem for a practicing oncologist such as possible cardiovascular complications (particularly arterial hypertension), which may lead to the cessation of this form of therapy. This article provides a brief overview of the mechanisms responsible for the above complications, including practical recommendations in the event such complications arise. A simple scheme of action for control of cardiovascular risk factors has been presented, which can improve the prognosis in this population of patients.

Key words: abiraterone acetate, enzalutamide, castration resistant prostate cancer, cardiovascular complications 


\section{INTRODUCTION}

Prostate cancer (PC) is the most frequently diagnosed neoplasm of the genitourinary system, being the most common malignant neoplasm in over 70-year-old men in Europe [1]. The slow clinical development of PC as well as the progress achieved in its early detection and efficacious treatment mean that the most common cause of mortality in the group of patients diagnosed with PC are deaths associated with cardiovascular disorders rather than directly with the cancer [2].

The current recommendations on pharmacotherapy of PC focus on hormonal treatment, including androgen ablation (ADT, androgen deprivation therapy), blockade of the androgen receptor with antiandrogens and so-called maximum androgen blockade (MAB).

Subsequent PC treatment lines include modern, $2^{\text {nd }}$ generation antiandrogens: abiraterone acetate, enzalutamide, apalutamide and darolutamide. Noteworthy, the applied modern PC treatment makes it possible to extend the survival rate and improve the quality of life of patients, also at the dissemination stage of the cancer. Thus, it becomes more important to understand and treat adequately the complications of an oncological therapy, as this can improve the prognosis among this population.

Androgen ablation performed by pharmacological castration entails the administration of agonists/analogues of the gonadotropin-releasing hormone $(\mathrm{GnRH})$, such as goserelin, leuprorelin or triptorelin, or antagonists of the luteinizing hormone releasing hormone (LHRH), such as degarelix. This form of hormonal therapy can be used for the treatment of PC in the generalized stage as well as in a neoadjuvant therapy or as a concomitant and supplementary therapy with radiotherapy in the treatment of cases with advanced local manifestations. Despite enormous clinical benefits it offers, we must not be tempted to ignore the undesirable side effects of this treatment, such as sexual dysfunction, decreased/ lost libido, fatigue, gynecomastia, hot flashes, osteoporosis, insulin resistance or cardiovascular diseases $[3,4]$.

The mechanism through which $\mathrm{GnRH}$ analogues act entails the inhibition of the pituitary secretion of luteinizing hormone and folliculotropic hormone, which consequently leads to a decrease in the blood testosterone level. Testosterone has a cardioprotective action and, by raising the production of nitric oxide in the endothelium of vessels and blocking calcium channels, it produces a vasorelaxant effect, which can help diminish the risk of myocardial ischaemia or development of arterial hypertension (AH) [5]. By lowering the level of testosterone, androgen abla- tion reduces the hormone's positive vaso- and cardioprotective effects, thereby increasing the cardiovascular risk. These adverse processes stem from lipid metabolism disorders, increased insulin resistance and more intensive inflammatory and procoagulant processes. An observational study by Keating conducted in 2016 [6] reported a 16\% increase in the risk of coronary disease and sudden cardiac death as well as an $11 \%$ rise in the risk of myocardial infarct in patients treated with a $\mathrm{GnRH}$ analogue due to advanced PC.

The administration of ADT also increases the risk of thromboembolic complications. In a meta-analysis completed in 2018 [7], a higher risk of deep vein thrombosis was demonstrated in patients treated with an analogue in a monotherapy and in combination with an antiandrogen drug, while pharmacological castration obtained with the use of ADT or by orchidectomy raises the incidence of pulmonary embolism $(\mathrm{HR}=2.26 ; 95 \% \mathrm{Cl}$ 1.78-2.86; $\mathrm{p}<0.001$; for ADT and $\mathrm{HR}=2.12$; $95 \% \mathrm{Cl} 1.44-3.11$; $p<0.001$ for surgical castration).

The use of hormonotherapy in the I line of treatment of disseminated PC usually makes it possible to control the disease for about 2 years. After that, most patients will have developed mechanisms of resistance to castration, which will lead to the progression of the illness. Having gained the knowledge of molecular mechanisms which underline the occurrence of the above development researchers were able to design new generations of antiandrogen drugs, which include irreversible inhibitors of androgen receptor (AR), enzalutamide, apalutamide and darolutamide, as well as the selective CYP17 inhibitor blocking the biosynthesis of androgens, i.e. abiraterone acetate. These drugs are increasingly often used also at earlier stages of PC therapy.

\section{ABIRATERONE ACETATE}

It needs to be highlighted that androgen suppression (i.e. therapy with LHRH analogues or orchidectomy) depresses the production of androgens in testes but does not affect the production of androgens in the adrenal glands or by the cancer itself. Better understanding of the effect of hormone metabolism on the progress of $\mathrm{PC}$ has resulted in the introduction of the term castration resistant prostate cancer (CRPC) to oncological terminology. Abiraterone acetate is a modern drug which is more effective at this stage of the illness. It is an oral, non-steroid selective inhibitor of the microsomal enzyme CYP17A1, which manifests its activity in the adrenal glands and in gonads. This drug blocks the biosynthesis of testosterone in the testes, ad- 
renal glands and in the neoplastic tissue, inhibiting the transformation of 17-hydroxypregnenolone to dehydroepiandrosterone. In consequence, the synthesis of testosterone and of 5 -a-dihydrotestosterone inducing proliferation of prostate cells is reduced. An additional effect of this action is the decreased concentration of cortisol in blood. Inhibition of CYP17A1 results in increased secretion of adrenocorticotropic hormone (ACTH) by the pituitary gland and consequently higher production of mineralocorticoids by the adrenal glands, which in turn leads to higher retention of fluids, hypokalaemia and $\mathrm{AH}$ [8].

Abiraterone acetate is administered in conjunction with pharmacological or surgical castration and a small dose of prednisone or prednisolone in the treatment of CRPC with metastases in adult males, asymptomatic or with negligible/low intensity of symptoms, after a failure of the applied androgen suppression and when chemotherapy is not yet recommended clinically, or in the treatment of castration resistant PC with metastases in adult males in whom the illness is progressing during the applied chemotherapy including docetaxel or afterwards [9].

In a LATITUDE study [10], the efficacy of the ADT treatment together with abiraterone acetate and prednisone versus the ADT treatment alone in the therapy of metastasizing, hormone-sensitive prostate cancer was compared. In this study, the unwanted side effects affecting the circulatory system that was most often reported by patients treated with abiraterone were $\mathrm{AH}$ and hypokalaemia, which might be associated with the elevated activity of hormones demonstrating the influence of mineralocorticoids produced by the adrenal glands. Such undesirable effects occurred in respectively 20 and 10\% of the patients included in the study (G3 intensity degree according to the Common Terminology Criteria for Adverse Events [CTCAE]). Toxicity towards the circulatory system was reported by $12 \%$ of the affected persons in the research group versus $8 \%$ in the control (including atrial fibrillations in about $1 \%$ of the patients administered abiraterone acetate).

A meta-analysis of five randomized studies on the therapy with abiraterone acetate [11] shows that its administration in any degree of toxicity is implicated as causing a higher risk of $\mathrm{AH}$ $(\mathrm{RR}=1.80 ; 95 \% \mathrm{Cl} 1.47-2.19 ; \mathrm{p}<0.001)$. Meanwhile, the researchers emphasize higher incidence of arterial hypertension at any degree of toxicity $(21.9 ; 95 \% \mathrm{Cl} 13.6-33.2 \%)$ in the group of patients administered abiraterone acetate and prednisone, where the reason for combining the two substances is to inhibit the secretion of ACTH and reduce unwanted effects due to an excess of hormones with mineralocorticoid action. In such cir- cumstances, elevated $\mathrm{AH}$ may arise from both an incomplete blockade of ACTH production by a small dose of prednisone and the pro-hypertensive activity of corticosteroids, which is a consequence of the stimulation of mineralocorticoid receptors and the ensuing mechanism of reabsorption of sodium and water [12].

\section{ENZALUTAMIDE}

Enzalutamide, a modern antiandrogen, is the first drug from the group of irreversible AR inhibitors which has been registered for treatment of hormone-sensitive PC with metastases in adult males in combination of ADT, in treatment of CRPC without metastases and in treatment of CRPC with metastases in adult males who are asymptomatic or have mild symptoms after a failure of ADT and who are not yet clinically recommended chemotherapy. Enzalutamide has also been registered as a drug for treatment of CRPC in adult men who have experienced progression of the illness during or after the treatment with docetaxel [13]. The beneficial effect of enzalutamide in PC stems from a few mechanisms. This drug blocks competitively the binding of androgens with the androgen receptor and the binding of the active androgen receptor with the DNA. Consequently, treatment with enzalutamide decreases the growth of prostate cancer cells, may cause the death of these cells and can lead to the regression of the neoplasm [14].

The efficacy of enzalutamide has been confirmed in three randomized, controlled placebo, multicentre clinical studies of the III phase (MDV3100-14 [PROSPER], CRPC2 [AFFIRM], MDV3100-03 [PREVAIL]) with the participation of patients with PC who experienced progression of the illness during ADT or patients after bilateral orchidectomy. The most common unwanted effect involving the circulatory system determined in the AFFIRM study [15] was arterial hypertension (6.6\% of patients in the group receiving enzalutamide, $3.3 \%$ in the control group). Similar results were obtained in the PREVAIL study [16] (13\% vs $8 \%)$. In this study, another side effect reported was cardiac arrhythmia manifested as atrial fibrillations in $2 \%$ of patients administered enzalutamide vs $1 \%$ in the placebo group. In all randomized clinical trials (RCT), ischaemic disease appeared in $3.7 \%$ of patients administered enzalutamide with ADT compared to $1.5 \%$ of patients who received placebo with ADT. Fifteen patients (0.4\%) administered enzalutamide and two patients $(0.1 \%)$ given placebo experienced an ischaemic heart disease event leading to death.

In a study by Hussain, completed in 2018 [17], where the efficacy of enzalutamide in treatment of CRPR without metastases 
was assessed, severe side effects concerning the cardiovascular system appeared in $5 \%$ of the patients given enzalutamide and in $3 \%$ of control patients. The most common unwanted effects leading to death were cardiovascular incidents in a group of 9 patients (1\%) treated with enzalutamide and $2(<1 \%)$ from the placebo group; they included myocardial infarct, circulatory and respiratory failure, acute cardiac failure and ventricular arrhythmias. The cited authors underlined that the risk factors related to the cardiological complications arising from treatment with enzalutamide were: age over 75 years, positive history regarding circulatory system diseases, $\mathrm{AH}$, diabetes and lipid metabolism disturbances.

Some studies also demonstrate that enzalutamide treatment can extend the QT in an ECG reading as well as increasing the risk of malignant arrhythmias (including torsade de pointes) [18]

\section{CARDIOVASCULAR COMPLICATIONS DUE TO THERAPY WITH THE SECOND GENERATION ANTIANDROGENS WHICH A PRACTICING PHYSICIAN SHOULD PAY SPECIAL ATTENTION}

As can be concluded from the results of RCT regarding the treatment of CRPC mentioned above, the oncological therapy using abiraterone acetate and enzalutamide creates a risk of the occurrence of several cardiological complications, of which the most common one is $\mathrm{AH}$ and all diagnostically undesirable cardiac and vascular incidents connected with hypertension.

The pathological mechanism of the development of $\mathrm{AH}$ during the treatment with abiraterone acetate is linked to the irreversible blocking of the CYP17A1 cytochrome, which shows the activity of 17-hydroxylase and 17,20-liase participating in the biosynthesis of androgens and cortisol. A decreased synthesis of the latter, via a negative feedback loop, causes a decrease in the secretion of ACTH by the anterior pituitary gland lobe. This mechanism intensifies the secretion of corticosterone, a precursor of aldosterone, by adrenal glands. In turn, this mineralocorticoid is responsible for retention of water in the body, hypokalaemia and development of $\mathrm{AH}$ [19]. In order to limit the overproduction of hormones that present mineralocorticoid action during the treatment with abiraterone acetate, the substitution of glycol corticosteroids is applied, as this treatment decreases the incidence of cardiological complications, although it can be responsible for stimulation of mineralocorticoid receptors with subsequent sodium and water reception and an increase in arterial blood tension [20].
The mechanism responsible for the development of $\mathrm{AH}$ in cases of the treatment of PC using a modern, strong AR inhibitor such as enzalutamide has not been elucidated completely. It appears that restrictions of the vasoprotective and metabolically positive activity of testosterone needs to be considered, which in turn translates into the clinically significant inhibition of the vasodilatory and antithrombogenic activity of the vascular endothelium as well as the promotion of insulin resistance of peripheral tissues and visceral obesity, that is the mechanisms which contribute to the pathogenesis of $\mathrm{AH}$ [21].

In medical practice, it is extremely important to bear in mind that general guidelines for therapeutic procedures in cases of $\mathrm{AH}$ connected with the administration of abiraterone acetate and enzalutamide do not diverge much from the guidelines for the therapy of $\mathrm{AH}$ applicable to the general population.

The current guidelines of the European Society of Cardiology (ESC), European Society of Hypertension (ESH) and the Polish Society of Arterial Hypertension (PTNT) provide considerably simplified recommendations for the AH therapy, which assume the broadest possible use of the simple treatment strategy with the use of single pill combination (SPC), which in most cases enables the patient to achieve the target values of arterial blood pressure (for most patients aged up to 65 years they are the systolic blood pressure of $<130 \mathrm{mmHg}$ and for patients aged 65 years and older - slightly above $130 \mathrm{mmHg}$; the diastolic blood pressure should be within the interval of $70-80 \mathrm{mmHg}$ ). Importantly, SPC with the use of two drugs should be implemented from the onset of the treatment and SPCs composed of three hypotension drugs are recommended at subsequent stages. The basic AH treatment strategy should always rely on the combination of a drug inhibiting the renin-angiotensin-aldosterone system (angiotensin-converting-enzyme inhibitor, ACE-I/angiotensin receptor blocker, ARB with the calcium channel blocker, CCB and/or a thiazide/thiazide-like diuretic). The subsequent phases of the treatment involve drugs inhibiting the renin-angiotensin-aldosterone axis, such as mineralocorticoid receptor antagonist (MRA), e.g. spironolactone or eplerenone, and drugs with other mechanisms of action: diuretics (e.g. torasemide), $\beta$ - and a-adrenolytics [22, 23]. Importantly, in a systematic review by Mc Menamin et al. [24] concerning the application of drugs blocking the renin-angiotensin-aldosterone system in oncological patients, it was observed that the treatment with ACE-I and ARB was associated with improved prognosis for men with PC.

Considering the available strategies for hypotensive treatment which should be applied in men treated with the second gen- 
eration antiandrogens (especially with abiraterone acetate), it is advisable to pay attention to these drugs whose role is to block the renin-angiotensin-aldosterone system (particularly the modern MRA such as eplerenone). The reason is the mechanism of action of abiraterone acetate, which causes inter alia overproduction of hormones with mineralocorticoid action in the adrenal glands, which in turn leads to hypertension, hypokalaemia and water retention in the body. Meanwhile, it would be incorrect to neglect the possible prohypertensive and proatherogenic effects of glucocorticoids, which are routinely administered together with abiraterone acetate in order to inhibit the adrenal-pituitary axis and to decrease the synthesis of mineralocorticoids by the adrenal glands $[19,20]$.

When analysing the principles for $\mathrm{AH}$ treatment in the discussed population of patients, it is useful to cite results of the research conducted by Gill et al. [25], who observed that men with $\mathrm{AH}$ and CRPC treated with abiraterone acetate might benefit more from the therapy with eplerenone than with abiraterone and prednisolone in terms of reduction of their body weight (due to fluid retention) and lower incidence of hypokalaemia (which may play a role in the prevention of arrhythmias). Moreover, another drug common in arterial hypertension treatment regimens which belongs to the MRA group - spironolactone, should not be administered routinely to this group of patients. The reason is its potential agonistic effect on AR, which is observed in cases of deficient androgens [26].

When selecting a hypotensive drug for a patient treated with abiraterone, it needs to be borne in mind that the latter intensifies the effect of drugs metabolized with the CYP2D6 cytochrome, such as metoprolol, propranolol or propafenone, the latter one being often prescribed in cases of atrial fibrillations [9].
When these drugs must be taken, caution is required or else the recommended dose may need to be lowered.

It is also necessary to remember about regular, monthly checkups of patients treated with abiraterone acetate for $\mathrm{AH}$, hypokalaemia and fluid retention. Men with a high cardiovascular risk should have these parameters checked every 2 weeks. In patients with lower potassium concentrations prior to or during the treatment with abiraterone, it is recommended to strive towards maintaining kalaemia at a level of no more than $4 \mathrm{mmol} / \mathrm{I}$ [9]

In view of the increasingly frequent diagnosis of PC, the availability of modern treatment methods (including hormonotherapy using $2^{\text {nd }}$ generation antiandrogen drugs, such as abiraterone acetate and enzalutamide) which prolong the longevity of patients, it is a significant challenge now to modify classic risk factors of the circulatory system diseases, the control of which may contribute to a further improvement in the prognosis for this population, exposed to the risk of cardiovascular complications.

The absence of universal recommendations concerning the above problems encouraged Bhatia et al. [21] to suggest the socalled $A B C D E$ algorithm, which summarizes in a simple manner all the guidelines regarding the most significant clinical problems and cardiovascular risk factors in men who undergo the ADT therapy. An evaluation of a patients in line with this procedure should be made at the onset of the treatment and then every 3 months (which is particularly important during the first 12 months of the hormonotherapy).

Table 1 shows a modified version of the ABCDE approach according to the ESC/ESH and PTNT recommendations.

TABLE 1.

Modified ABCDE algorithm to facilitate an evaluation and control of cardiovascular risk factors in men with CRPC treated inter alia with the $2^{\text {nd }}$ generation antiandrogens (based on [21-23]).

\begin{tabular}{|c|c|c|}
\hline A & Awareness & The awareness of the patient regarding typical symptoms of circulatory system diseases \\
\hline & Aspirin (acetylsalicylic acid, ASA) & $\begin{array}{l}75-150 \mathrm{mg} / 24 \mathrm{~h} \text { administered to patients with arterial hypertension and cardiovascular complications } \\
\text { (secondary prevention) }\end{array}$ \\
\hline B & Blood pressure (hypertension) & $\begin{array}{l}\text { Target values: } \\
\text { Aged below } 65 \text { years.: } \mathrm{SBP}<130 \mathrm{mmHg} \text {, DBP } 70-79 \mathrm{mmHg} \\
\text { Aged } 65 \text { years and over: SBP } 130-139, \text { DBP } 70-79 \mathrm{mmHg}\end{array}$ \\
\hline C & Cholesterol & $\begin{array}{l}\text { Hypolipemic therapy using statins in patients with hypertension and moderate or high cardiovascular risk } \\
\text { (targeted values } \mathrm{LDL}<100 \mathrm{mg} / \mathrm{dl} \text { and } \mathrm{LDL}<70 \mathrm{mg} / \mathrm{dl} \text { ) }\end{array}$ \\
\hline & Cigarettes & $\begin{array}{l}\text { Complete cessation of tobacco smoking; possible behavioural therapy and pharmacotherapy to help quit } \\
\text { the addiction }\end{array}$ \\
\hline D & Diabetes mellitus & Regular control of glycaemia; if therapy recommended - metformin (unless counterindicated) \\
\hline & Diet & $\begin{array}{l}\text { Diet rich in fruit, vegetable, whole-grain products, limited intake of saturated lipids } \\
\qquad \begin{array}{c}\text { Vitamin } D \text { and calcium supplementation } \\
\text { Avoiding alcohol intake }\end{array}\end{array}$ \\
\hline $\mathrm{E}$ & Exercise & 150 min of moderate or 75 of intensive physical exercise weekly \\
\hline
\end{tabular}




\section{CONCLUSIONS}

The hormonal therapy for $P C$ is a popular method of the treatment of this neoplasm. Although it is usually well tolerated by patients, it is associated with the risk of cardiovascular complications, which worsen the prognosis. Both classical ADT and combined with drugs from the group of modern antiandrogens bring about a higher risk of cardiotoxicity, mainly a more frequent incidence of $\mathrm{AH}$. In everyday clinical practice, it is important to ensure that patients with CRPC treated conservatively with the use of abiraterone acetate and enzalutamide are monitored regularly for the possibility of this complication, which is often accompanied by hypokalaemia and symptoms of fluid retention (including $\mathrm{AH}$ mentioned above or peripheral oede$\mathrm{ma})$. It is worth noticing that the general guidelines for treatment of $\mathrm{AH}$ in this population of patients do not deviate much from the current recommendations by ESC/ESH and PTNT, and the drugs that should be preferred while selecting a therapeutic strategy are the ones which have an inhibitory effect on the renin-angiotensin-aldosterone system (ACEI, ARB and MRI; in the latter case the indicated drug is eplerenone). Moreover, the routine application of the simple algorithm, $A B C D E$, can help to control risk factors of cardiovascular diseases in this group of patients, thereby improving their prognosis.

\section{References}

1. Krajowy Rejestr Nowotworów. http://onkologia.org.pl/nowotwory-zlosliwe-gruczolu-krokowego-c61 (access: 12.07.2021).

2. Epstein MM, Edgren G, Rider JR et al. Temporal trends in cause of death among Swedish and US men with prostate cancer. J Natl Cancer Inst. 2012; 104: 1335-42. http://doi.org/10.1093/jnci/djs299.

3. Nguyen PL, Alibhai SMH, Basaria S et al. Adverse effects of androgen deprivation therapy and strategies to mitigate them. Eur Urol. 2015; 67(5): 825-36.

4. Tzortzis V, Samarinas M, Zachos I et al. Adverse effects of androgen deprivation therapy in patients with prostate cancer: focus on metabolic complications. Hormones (Athens). 2017; 16: 115-23. https://doi.org/10.14310/horm.2002.1727.

5. Gupta D, Lee Chuy K, Yang JC et al. Cardiovascular and metabolic effects of androgen-deprivation therapy for prostate. Cancer Oncol Pract. 2018; 14(10): 580-7.

6. Keating NL, O'Malley AJ, Smith MR. Diabetes and cardiovascular disease during androgen deprivation therapy for prostate cancer. J Clin Oncol. 2006; 24: 4448-56. https://doi.org/10.1200/JCO.2006.06.2497.

7. Guo Z, Huang Y, Gong L et al. Association of androgen deprivation therapy with thromboembolic events in patients with prostate cancer: a systematic review and meta-analysis. Prostate Cancer Prostatic Dis. 2018; 21: 451-60.

8. Rehman Y, Roseberg JE. Abiraterone acetate: oral androgen biosynthesis inhibitor for treatment of castration-resistant prostate cancer. Drug Des Devel Ther. 2012; 6: 13-8.

9. Charakterystyka produktu leczniczego Zytiga ${ }^{\oplus}$. https://ec.europa.eu/health/documents/community-register/2016/20161109136263/anx_136263_ pl.pdf (access: 12.07.2021)

10. Fizazi K, Tran N, Fein L et al. Abiraterone plus prednisone in metastatic, castration-sensitive prostate cancer. N Engl J Med. 2017; 377: 352-60. https:// doi.org/10.1056/NEJMoa1704174.

11. Zhu X, Wu S. Risk of hypertension in Cancer patients treated with Abiraterone: a meta-analysis. Clin Hypertens. 2019; 25: 5. https://doi.org/10.1186/ s40885-019-0110-3.

12. vanDorst $\mathrm{DCH}$, Dobbin $\mathrm{SJH}$, Neves KB et al. Hypertension and prohypertensive antineoplastic therapies in cancer patients. Circ Res. 2021; $128: 1040-61$.

13. Xtandi - charakterystyka produktu leczniczego. https://ec.europa.eu/health/documents/community-register/2016//20161212136636/anx_136636_ pl.pdf (access: 12.07.2021)

14. Schalken J, Fitzpatrick JM. Enzalutamide: targeting the androgen signalling pathway in metastatic castration-resistant prostate cancer. BJU Int. 2016; 117(2): 215-25

15. Scher HI, Fizazi K, Saad F et al. Increased survival with enzalutamide in prostate cancer after chemotherapy. N Engl J Med. 2012; 367: 1187-97. https:// doi.org/10.1056/NEJMoa1207506.

16. Beer TM, Armstrong AJ, Rathkopf DE et al. Enzalutamide in metastatic prostate cancer before chemotherapy. N Engl J Med. 2014; 371:424-33. https:// doi.org/10.1056/NEJMoa1405095.

17. Hussain M, Fizazi K, Saad F et al. Enzalutamide in men with nonmetastatic, castration-resistant prostate cancer. N Engl J Med. 2018; 378: 2465-74. https://doi.org/10.1056/NEJMoa1800536.

18. Salem JE, Yang T, Moslehi JJ et al. Androgenic effects on ventricular repolarization: a translational study from the international pharmacovigilance database to iPSC-cardiomyocytes. Circulation. 2019; 140: 1070-80. https://doi.org/10.1161/CIRCULATION AHA.119.040162.

19. Attard G, Reid AH, Auchus RJ et al. Clinical and biochemical consequences of CYP17A1 inhibition with abiraterone given with and without exogenous glucocorticoids in castrate men with advanced prostate cancer. J Clin Endocrinol Metab. 2012; 97(2): 507-16.

20. Kosicka K, Główka FK, Kośla A et al. Rola glikokortykosteroidów w etiologii nadciśnienia tętniczego. Nadciśnienie Tętnicze. 2010; 14(3): $208-15$.

21. Bhatia N, Santos M, Jones LW et al. Cardiovascular effects of androgen deprivation therapy for the treatment of prostate cancer. Circulation. 2016; 133; 5: 537-41.

22. Williams B, Mancia G, Spiering W et al. 2018 ESC/ESH Guidelines for the management of arterial hypertension. Eur Heart J. 2018; 39: 3021-104. 
23. Tykarski A, Filipiak KJ, Januszewicz A et al. Zasady postępowania w nadciśnieniu tętniczym - 2019 rok. Wytyczne Polskiego Towarzystwa Nadciśnienia Tętniczego. Nadciśnienie Tętnicze w Praktyce. 2019; 5: 1-86.

24. Mc Menamin UC, Murray LJ, Cantwell MM et al. Angiotensin-converting enzyme inhibitors and angiotensin receptor blockers in cancer progression and survival: a systematic review. Cancer Causes Control. 2012; 23: 221-30.

25. Gill D, Gaston D, Bailey E et al. Efficacy of eplerenone in the management of mineralocorticoid excess in men with metastatic castration-resistant prostate cancer treated with abiraterone without prednisone. Clin Genitourin Cancer. 2017; 15(4): e599-602.

26. Dhondt B, Buelens S, Van Besien J et al. Abiraterone and spironolactone in prostate cancer: a combination to avoid. Acta Clin Belg. 2019; 74(6): 439-44. https://doi.org/10.1080/17843286.2018.1543827.

Authors' contributions:

Radosław Grabysa: 60\%; Agnieszka Chmielewska: 40\%.

Conflict of interests:

The authors declare no conflict of interest regarding the publication of this article.

Financial support:

None.

Ethics:

The authors had full access to the data and take full responsibility for its integrity.

All authors have read and agreed with the content of the manuscript as written.

The paper complies with the Helsinki Declaration, EU Directives and harmonized requirements for biomedical journals. 